\title{
Celebrity capital, field-specific aesthetic criteria and the status of cultural objects: The case of Masked and Anonymous
}

\author{
Article accepted for publication in European Journal of Cultural Studies
}

\section{Simon Stewart}

University of Portsmouth, UK

\begin{abstract}
This article probes the explanatory value of the concept of celebrity capital in helping us to grasp the fate of celebrities and the cultural objects they produce when they move across to other fields. However, the article seeks to do more than this: with reference to the example of the singer-songwriter Bob Dylan's incursion into the cinematic field, where he co-wrote Masked and Anonymous (2003), it contributes to debates by examining the significance of field-specific aesthetic criteria in helping us to gain insight into the aesthetic value of cultural objects. While Dylan's celebrity capital gave him access to a number of 'A-List' celebrity actors, the aesthetic dimension of the film did not have a meaningful relation to the state of play in the cinematic field and so the film was, in the main, critically panned. So, Masked and Anonymous made Dylan's boundarycrossing journey in reverse: it retreated to the field of popular music where its aesthetic properties were warmly received when considered in relation to Dylan's wider body of work. Meanwhile, it was difficult for the harshest critics to ignore the aesthetic value that Dylan's wider body of work had accumulated over time. There is, then, a temporal dimension of aesthetic appraisal that needs to be considered, even when reviews are considered at a particular historical conjuncture. In this analysis of field-specific aesthetic criteria, we see that boundary work is effective in diminishing the status of a cultural object (Masked and Anonymous), but we also see that each critic has only limited sway in the face of the totality of judgements which emerges as a supra-individual voice, heterogeneous and full of contradictions, deriving from all those who make evaluative judgements in the field of culture.
\end{abstract}

\section{Keywords}

Aesthetic value, Bob Dylan, celebrity, celebrity capital, field, field-specific aesthetic criteria, Masked and Anonymous, status 
The concept of celebrity capital, defined as 'accumulated media visibility through recurrent media representations' (Driessens, 2013: 553), enables us to understand how prominent celebrities, with encouragement from those who stand to gain commercially from the project, find themselves in a strong position to enter other cultural fields and to try their hand at being (for example) novelists, painters, authors of children's fiction, actors or even political campaigners. These celebrities are not inhibited by the usual entry restrictions that prohibit most of us from embarking on such ventures. But what happens to the cultural objects they produce when in alien territory? The article uses the example of the singersongwriter Bob Dylan's incursion into the cinematic field, where he starred in and co-wrote Masked and Anonymous (M\&A) (2003). Although Dylan did not direct M\&A, it experienced a similar fate to Renaldo and Clara, the film he directed in the late 1970s, which was praised for its extensive footage of Dylan's live musical performances but derided for its dramatic content. While Dylan's celebrity capital gave him access to a number of prominent celebrity actors such as Penelope Cruz, Luke Wilson, Jessica Lange and Jeff Bridges, and cutting-edge director, Larry Charles, the aesthetic dimension of $M \& A$ did not have a meaningful relation to the state of play in the cinematic field and so the film was, in the main, critically panned. M\&A made Dylan's boundary-crossing journey in reverse: it retreated to the field of popular music where its aesthetic properties were warmly received by critics and fans when considered in relation to Dylan's wider body of work. However, despite the film critics' best efforts to police the boundaries of their field, the aesthetic value of Dylan's wider body of work, accrued over time in the neighbouring field of popular music, is very much present in the reviews. This article, which is based on a thematic analysis of reviews of M\&A, extends the reach of discussions of celebrity capital and field analysis by focusing in on field-specific aesthetic criteria in determining the status of the cultural objects produced as celebrities enter new cultural fields. It draws attention to the accumulative aspect of aesthetic value, which emerges, despite all the contradictions and contestations inherent to its formation, as a supra-individual voice from all those making (and those who have made) evaluative judgements in the cultural field.

Olivier Driessens (2013) utilises the Bourdieu-derived concept of celebrity capital to gain more precision in understanding celebrity and to account for the fact that celebrity can be converted into other capitals and resources. In contrast with the concept of symbolic capital, which refers to field-specific recognition (such as the prestige bestowed on a prominent physicist by other 
scholars in the field), celebrity capital is a type of renown that derives from accumulated media visibility gained through repeated media representations, and can work across social fields (Driessens, 2013). The concept enables us to better understand why it is possible for celebrities to cross boundaries from one social field to another. So we see, for example, how Russell Brand utilised his celebrity capital - gained through his work as a television presenter and comedian - to enter the field of politics and present an online political show, The Trews, in the build-up to the 2015 General Election in the United Kingdom. While it would be possible for anyone with some basic technologies (a mobile phone and access to Internet broadband) to film and upload a political show directed from their bedroom - 'ordinary people' would not have the celebrity capital or social capital that would enable them to entice prominent politicians to be interviewed. There are, of course, limits to what celebrity capital can enable and it is not always easy to translate one form of capital to another (Bourdieu, 1986). While possession of a large amount of celebrity capital might enable a boundary crossing, 'it does not automatically imply its recognition, when other forms of capital are more important in that particular field' (Driessens, 2013: 551). Its deployment in other fields disrupts the value of the various capitals that are specific to these fields and this means that attempts to convert celebrity capital into other capitals often meet with resistance (Driessens, 2013: 555). David Giles (2015) relates, for example, that when the popular musician Paul McCartney tried, on numerous occasions, to enter the field of classical music, the 'easy bit' was using his celebrity capital in order to promote concerts in prestigious halls, recruit highly rated composers, musicians and soloists to enable his musical vision, and sell vast numbers of the albums he produced. What was more difficult for McCartney was converting his celebrity capital into cultural capital and gaining the respect of those holding sway in terms of the classical field's evaluative judgements. Prominent critics in the field, almost without exception, rejected McCartney's classical compositions as trite, devoid of compositional range and thus bereft of value (Giles, 2015).

In order to contribute to the growing body of research on celebrity capital, this article draws attention to something that is often neglected in accounting for the success or otherwise of boundary crossings: the field-specific aesthetic criteria that serve as markers of what makes the grade. I draw attention to the ways in which M\&A was critically received. First, in the cinematic field, I find that critical discourse was largely hostile to Dylan's boundary crossing. M\&A, it was suggested, did not connect, through the direction, screenplay or script, to 
the state of play in the cinematic field. In contrast, the film was warmly received back in the field from which Dylan set off on his journey: the film's aesthetic properties were very much aligned with the state of play in the field of popular music and served to augment the perceived significance of Dylan's creative output. So, when he left the hostile territory of the cinematic field, Dylan retreated to where he was initially consecrated and he was followed soon after by M\&A. However, even as the film critics pushed M\&A on its way, they were only too keen to make claims about the value of the music and songwriting contained in the film. Moreover, the aesthetic value that has accrued over time to Dylan's songwriting was very much present in the reviews: this value proves to be more able to cross boundaries than Dylan himself. What do we learn from this? It is argued that we can gain a stronger understanding of aesthetic value if we are attentive to the ways in which field-specific aesthetic criteria are discussed and contested, in innumerable evaluative judgements, adding to or subtracting from the status of cultural objects over time.

\section{Field-specific aesthetic criteria}

Field-specific aesthetic criteria are those that accord with a cultural or artistic field and the current state of play in that field. Pierre Bourdieu's $(1993,1996)$ analysis of cultural production offers a theoretical model with which to envisage these criteria though, as we shall see, he does not give them full attention. Bourdieu's (1998) notion of field is,

A structured social space, a field of forces, a force field. It contains people who dominate and others who are dominated. Constant, permanent relationships of inequality operate inside this space, which at the same time becomes a space in which the various actors struggle for the transformation or preservation of the field. (p. 40)

According to Bourdieu (1993, 1996, 1998, 2004), society is made up of a number of overlapping fields and subfields, each of which has its own laws, which distinguish it from the wider field of power. The more autonomy that a field has, the more it has the power to 'define its own criteria for the production and evaluation of its products' (Bourdieu, 1993: 115). Just as fields can go through a process of evolution, whereby they gain autonomy and become clearly demarcated from the wider logic of power and economy, they can, through involution, regress so that they adhere to external laws such as the logic of profit that more generally characterises neoliberal capitalism (Bourdieu, 
2003). Each field has to a greater or lesser extent, over time, established its own laws of functioning. For example, Bourdieu (2003) writes that it took more than five centuries for the conditions of the cultural field to be ready for a Picasso to come to the fore. In the region of the cultural field where its rules are most strictly applied - such as where the logic of art for art's sake applies - there is more autonomy. In contrast, at the other pole, the field is heteronomous and is more likely to be governed by commercial interests. We face several challenges in applying Bourdieu's field analysis to contemporary cultural conditions. First, as has been widely noted, much of Bourdieu's writing about cultural production focuses on the 19th-century literary and artistic scenes in France and so the broader applicability of his findings has been questioned. Moreover, it is debatable whether it is possible to talk about a singular field of cultural production in the 21st century, when it might be more appropriate to approximate (at best) a number of overlapping subfields. Second, Bourdieu's field analysis was utilised in order to understand highbrow culture, and so it requires a degree of imagination to apply it to fields of popular culture such as those discussed in this article (Fowler, 2016). Third, as Savage and Silva (2013:112) note, Bourdieu's national focus needs to be extended so that it is possible to gain a greater 'global' comparative perspective on cultural production. If, for example, we speak of a field of culture, to what extent does this field now stretch across borders and beyond the boundaries of the nation state? While we might expect that a cultural form such as comedy retains a high degree of national specificity, the same surely cannot be said of popular music, the study of which foregrounds hybridity and 'rests on the assumption that there is no such thing as a culturally "pure" sound' (Frith, 1989: 3). Fourth, it has been argued that field analysis can gain from augmenting its focus on struggle and competition by paying attention to cooperation, shared passion and intensities (Gonsalves, 2015; Hennion, 2001; Savage and Silva, 2013). As Gonsalves (2015: 441) observed in her study of Indian publishers at the Frankfurt Book Fair, Indian publishers, as relative newcomers to the field, did not seek to augment their position through strategies of rupture or revolution. Instead, they utilised strategies of friendliness. Fifth, greater consideration needs to be given to cultural objects (more broadly, as Savage and Silva (2013: 112) argue, field analysis needs to be imbued with an understanding of materiality - including objects and bodies). Bourdieu has been accused of reducing his analysis of culture to a 'Hobbesian power struggle between interests' (Garnham, 1993: 185) and treats the cultural object as little more than a symbol in a wider game of power (Hennion, 2001, 2007). Extending these 
critiques, Highmore (2016) makes the contentious but perceptive argument that Bourdieu is not actually concerned with the aesthetic dimension of taste at all; he 'was not actually interested in taste and rarely addressed its particular qualities in his work' (p. 547).

This article contributes to debates by focusing on the field-specific aesthetic criteria that come into play when celebrities cross boundaries into other cultural fields. The concept of field allows us to envisage numerous overlapping fields, each with different stakes, rules and specific criteria of judgement. Analysing field-specific aesthetic criteria enables us to see why some celebrity boundary crossings succeed, while others fail. Celebrity capital enables a high degree of field mobility but does not necessarily convert into artistic success. Judgements about the worth of things are fiercely contested within the various arenas that make up our cultural life and far from being a relativist free-for-all there are clear rules according to which merit is bestowed. Bourdieu $(1993,1996)$ alludes to these criteria but they are very much in the background of his analysis. As Austin Harrington (2004) observes, 'Bourdieu's analytical tendencies ... tend to be biased towards the side of functional sociological analysis at the expense of understanding for normative validity in aesthetic concerns' (p. 109). This article seeks to redress the lack of attention to these criteria and brings them out into the foreground of analysis. Questions of value are often neglected or left stored in a strategic 'black box' by scholars in sociology and cultural studies (Harrington, 2004: 39). Therefore, this article extends the reach of conventional field analysis by focusing on the appraisal of a specific cultural object (M\&A) in relation to field-specific aesthetic criteria and broader repertoires of aesthetic value (Stewart, 2012, 2013, 2017).

\section{Methods}

This article presents the findings of a study that conducted a thematic analysis of 76 reviews of M\&A. The reviews were published in the United States, Canada, Australia and the United Kingdom, around the time of the film's release in 2003 and in 2004 (when M\&A was released on DVD). I analysed all English language reviews that it was possible to access via Nexis, Google and through critic or fan sites. This search was conducted 14 years after M\&A's release and so some of the reviews listed on sites such as Rotten Tomatoes were no longer accessible. Thematic coding was deployed in order to segment, categorise, summarise and generally make sense of the critics' evaluative judgements (Ayres, 2012). Thematic analysis was then deployed to identify and analyse patterns within the data (Braun and Clarke, 2006). I conducted a theoretically driven thematic analysis, with the generation of codes framed in relation to the above- 
mentioned field theory (Bourdieu, 1993; Coffey and Atkinson, 1996). However, in the process of coding, there was an oscillation between theory and data, between phases of deductive and inductive work (Born, 2010: 198). The codes were clustered around several overarching themes including (for example) popular music-specific aesthetic criteria, film-specific aesthetic criteria and celebrity capital. Beneath surface-level pronouncements about the 'good' and 'bad' aspects of the film, there was a broad acknowledgement of the aesthetic significance of Dylan's wider creative output: this was present even in many of the most caustic reviews. To avoid unnecessary repetition, particularly vivid illustrative examples were selected in order to demonstrate the significance of the prominent themes (Braun and Clarke, 2006). The research was carried out within a constructivist framework, focusing on the ways in which meaning is socially produced and making no assumptions about a necessary correspondence between verbal utterances and behaviour or genuinely held beliefs (Fielding and Thomas, 2008). Moreover, it was instructive to bear in mind that film and music critics are performing their role, writing review columns that serve, primarily, to entertain. These critics are not, therefore, totally disinterested, in the Kantian mode, that is, 'the faculty of estimating an object or a mode of representation by means of delight or aversion apart from any interest' (Kant, 2008 [1790]: 131), but are, in Bourdieu's (1998) terms, constrained by the tacit assumptions of the field within which they operate. Criticism is defined by John Corner (2013) as 'the making of considered claims about the nature and values of a cultural product grounded in analysis and evidence and proceeding by argument' (p. 2). More specifically, this article focuses on film reviews, which, according to Kersten and Bielby (2012), 'present a balanced evaluation of the film's principle features through positive and negative commentary in which specific details as well as the general picture are considered' (p. 188). However, it is worth pointing out that reviews discussed in this article are anything but balanced: they are, variously, socially situated performances of evaluative judgement with specific audiences in mind, whether cinema-goers or fans of popular music.

Film critics play a crucial role as cultural intermediaries in negotiating the state of play in the cinematic field. In addition to this, in borrowing or adapting modes of analysis and the vocabulary of criticism from the field of visual arts, they have played a crucial role in gaining legitimacy for cinema as an art form (Baumann, 2001). However, as Kersten and Bielby (2012) found in their analysis of film reviewing criteria, critics have, over time, changed their interpretive focus in the light of broad cultural changes as indicated by the perceived shift 
from cultural snob to omnivore (Peterson and Kern, 1996). For example, films that are critically praised, and are evaluated on the basis of auterism, are now also judged in relation to the more immediate concerns that characterise popular taste such as the extent to which they offer a culturally meaningful viewing experience. Similarly, films that receive predominantly popular acclaim (i.e. blockbusters) are often evaluated at least to some extent on the basis of their formal aesthetic properties (Kersten and Bielby, 2012). The reviews in this study are drawn from journalists and publications with varying degrees of cultural legitimacy, from those who reach large national and international readerships and are accustomed to utilising an 'aesthetic disposition' - drawing attention to the formal aesthetic properties of the films, in publication such as The New York Times, The Guardian, Rolling Stone and The Globe and Mail, to those which utilise a more popular cultural register, such as USA Today and Internet sites such as Ain't It Cool News (Bourdieu, 1984). Reviews are also drawn from popular fan sites that give space to amateur critics and, in doing so, provide outlets for evaluative judgements that work with and against the authority of established publications (Corner, 2013; Jacobs et al., 2015). A comparison of the different registers and habitus of these various journalists and publications is beyond the scope of this article, as are the ways in which readers interpreted the reviews. The main focus is the analysis of the deployment of field-specific criteria in the reviews written by film and popular music critics. The reviews gathered from the field of popular music are fewer, but count among them those written by consecrated popular music and Dylan scholars such as Andrew Motion (the former British Poet Laureate), Michael Gray, Sean Wilentz and Greil Marcus, as well as those penned by 'amateurs' and posted on a prominent Dylan fan site. ${ }^{1}$

To provide some context in order to better understand its critical reception, it is worth noting that M\&A was Charles's feature debut as director and it was filmed in just 20 days, on a limited budget, with the BBC as a co-production partner. The screenplay was cowritten by Rene Fontaine and Sergei Petrov, pseudonyms for Charles and Dylan - neither of whom were experienced in writing film scripts. Released in 2003, M\&A is set 'in a war-torn country, the United States as a vaguely Latin American banana republic' (Leeder, 2012: 183184). Dylan plays the character of Jack Fate, a musician whose character resonates with our understanding of Dylan's off-screen persona: Fate is enigmatic, world-weary and speaks in riddles. We are thus encouraged to view Fate as Dylan, a task made easier for us by a soundtrack dominated by Dylan's songs. Fate has been languishing in jail but is freed so that he can play a benefit concert for the victims of the country's revolution. M\&A has a dystopian, 
futuristic setting, but sardonic references are made to celebrities of our times with Sting, Bruce Springsteen, Paul McCartney and Billy Joel cited as having turned down the opportunity to perform at the benefit concert. The concert never actually happens and the plot takes a dark turn when the dictator (who happens to be Fate's father) dies, there is a coup and, subsequently, an escalation of military violence. Fate ends the film going back to jail for the murder of a journalist, even though the murder was actually committed by Fate's loyal friend.

\section{Celebrity capital}

It would simply not be possible for an ordinary person to do what Dylan did in 2003 , that is, to co-write a film script and make the project that became $M \& A$ happen. Of course, most celebrities (let alone ordinary people) would struggle to be able to attract A-List Hollywood celebrities to appear in a film for a fraction of their usual price. If Dylan's celebrity capital enabled him to make the boundary crossing to the cinematic field, it also played a major role in enticing the other actors to appear in M\&A. In the reviews, 24 sources produced 29 references drawing attention to Dylan's celebrity status in attracting co-stars. Dylan attracted 'about half the Hollywood acting pool' (Lacey, 2003), and Charles was able to recruit 'a veritable Who's Who of Hollywood' (Thayil, 2003). The suggestion is made that the actors have 'fallen over themselves' to appear alongside Dylan (Baumgarten, 2003) and were 'helplessly drawn to his flame' (Errigo, 2003) and keen to 'rub against the rock god' (Peary, 2003). Here we see the explanatory value of the concept of celebrity capital and its prominence as a theme. It helps us to understand why Dylan was able to make a film with these actors. As Roger Ebert (2003), the prominent film critic, observed, ' $[\mathrm{t}]$ he movie's cast is a tribute to Dylan's charisma'. Dylan's 'charisma' is clearly linked to the type of celebrity status referred to by Chris Rojek (2000) as 'achieved' - that is, derived 'from the perceived accomplishments of the individual in open competition' (p. 18), as compared to the attributed celebrity of those whose celebrity status derives from the being designated significant and noteworthy by cultural intermediaries, or the ascribed celebrity status of those whose celebrity status stems from family lineage. Dylan's charisma, which, in Max Weber's (1946 [1915]: 295) terms, is based on 'belief in the extraordinary quality of the specific person', is nevertheless translated into 21st-century celebrity capital through the accumulation of Dylan's visibility in popular culture as 'the spokesman of a generation', the inventor of literate rock and roll, and the celebrated author of songs that are now part of the canon of popular music 
such as Blowin' in the Wind, Like a Rolling Stone and The Times They Are aChangin'. It is not difficult to see, therefore, how Dylan's celebrity capital enticed the A-List actors Jeff Bridges, Penelope Cruz, John Goodman, Jessica Lange, Luke Wilson, Angela Bassett, Mickey Rourke and Christian Slater to appear in M\&A.

Dylan's venturing forth into a 'foreign' field for M\&A was not his first nor would it be his last celebrity-capital-enabled boundary crossing. He directed the film Renaldo and Clara (1978) and acted in Pat Garrett and Billy the Kid (1973) and Hearts of Fire (1986). Dylan has written two books: the extended prose poem Tarantula (1965) and the autobiography, Chronicles (2004). He is also a painter and sculptor and has staged a number of exhibitions around the world. In order to better understand Dylan's boundary crossings, the use of 'celebrity capital' needs to be augmented with awareness of other forms of capital that enhance Dylan's ability to freely cross over into other fields. For a start, Dylan's celebrity status does not derive entirely from accumulated media visibility. He has, over the decades, increasingly kept a distance from the media. Therefore, we need to consider the abundance of a particular type of cultural capital that he has accumulated over the years: institutional cultural capital. Institutional cultural capital is acquired when institutions bestow recognition on the cultural capital held by a particular individual (Bourdieu, 1986). Prestigious institutions, in doing so, demonstrate 'the power to show forth and secure belief, or, in a word, to impose recognition' (Bourdieu, 1986: 51). Before making M\&A, Dylan had significant institutional cultural capital and his possession of this form of capital has continued to grow. Within the field in which he is most prominent popular music - he has received 27 nominations and he has won 12 Grammy Awards. His successes include Album of the Year, with Time out of Mind (1998), Best Contemporary Folk Album, with Love and Theft (2002), and Best Historical Album, with The Bootleg Series Volume 11: The Basement Tapes Complete. He has been inducted into the Grammy Hall of Fame and the Rock and Roll Hall of Fame. Outside the field of popular music and highlighting the wider cultural significance of his work, Dylan has been awarded numerous honours including a Tom Paine Award (1963), an Honorary Doctorate of Music by Princeton University (1970) and St. Andrews University (2004), Commandeur des Artes et des Lettres (1990), Kennedy Center Honors (1997), Pulitzer Prize Special Citations and Awards (2008), National Medal of Arts (2009) and Officier de la Legion d'honneur (2013). In the cinematic field, he won an Academy Award (Oscar) for Best Original Song (2000) with his song Things Have Changed (from the film Wonder Boys). Meanwhile, the Presidential Medal of Freedom (2012) gave him stature in the wider field of power with the award presented by 
President Barack Obama. Dylan's stock of institutional cultural capital was given the most significant boost when he was awarded the Nobel Prize for Literature in 2016. Dylan's cultural competences have thus been imbued with a form of permanence, a guarantee of approve that is distinct from the fluctuations in value of cultural capital experienced by nonconsecrated artists and writers who have to prove their worth in the moment. However, despite Dylan's significant volumes of celebrity and institutional capital, the project he pursued - with M\&A - was deemed to be a failure and was critically panned.

\section{Film-specific aesthetic criteria}

According to most of the film critics, M\&A is, quite simply, a bad film. For example, it is described as 'a redolent mess' (Lacey, 2003), 'the biggest waste of talent' (Puig, 2003), an 'enervating wreck' (Lane, 2003), 'an unholy, incoherent mess' (Scott, 2003) and 'a strong contender for the worst movie of the century' (Lumenick, 2003). Only 7 of the 62 film critics' reviews were, broadly speaking, positive about M\&A. A year or so after its release, Peter Bradshaw (2004) included it in his list of Hollywood's greatest 'straight to video' flops, suggesting that M\&A occupies 'the most bizarre circle of video hell' (p. 7). The critics are explicit in stating that the film's aesthetic properties do not accord with those of contemporary cinema and they express a sense of outrage that they have had to endure watching this film. The field-specific aesthetic criteria on which their judgements are based were many and varied but, broadly speaking, they coalesce around the following: M\&A's incoherence of plot and direction, poor screenplay and poor acting. The general sense they convey is that M\&A has no sense of purpose and seems to be made up of a series of fragmented scenes. Comparisons are made with the ways in which Dylan - in the course of his songwriting - draws together various disconnected elements, but in the case of M\&A this weaving together 'plays like a parody of a bad Dylan song' (Alter, 2003), and is 'too nebulous and too resistant to narrative principles to hold together for a full two hours' (Davies, 2003). The scenes are stitched together with no overall sense of plot or purpose. Some of the blame points to Charles, who is argued to have made a 'disastrous debut as big-screen director' (Lumenick, 2003), and is 'in over his head in big-screen allegory' (Thomas, 2003). Charles, they argue, 'fails to provide one essential: direction' (Travers and Scaggs, 2003) and 'doesn't have a clue how to jell the many elements of this three-ring circus' (McCarthy, 2003). Will Dana (2004), in Rolling Stone, writes that a sense of confusion permeates the project and 'all involved basically admit they have no idea what the movie is about'. 
The screenplay is also deemed to be poor, with Dylan and Charles accused of producing 'high-flying poppycock' (Atkinson, 2003) and 'incomprehensible dialogue' (Anderson, 2003). The writing consists of 'incoherent raving juvenile meanderings' (Ebert, 2003), 'overburdened by endless self-important chatter and a pervading sense of ennui' (Homaday, 2003) and 'pretentiously gnomic when not simply ridiculous' (Lacey, 2003). Peter Rainer (2003) argues that the dialogue 'is a high-toned meta-philosophical babble that I'm tempted to call stream-of-consciousness, except that would be unfair to consciousness'. M\&A's screenplay is deemed to have neither the drive nor sense of purpose that characterises Dylan's song lyrics. It also lacks the wit and quick-fire dialogue that characterise Charles's successes with the television comedies Seinfeld and Curb Your Enthusiasm.

Dylan's acting, they argue, is wooden: he 'could easily have been replaced by a piece of wood with his face painted on it' (Phipps, 2003), and is awkward and inexpressive. In fact, it is suggested that Dylan's performance could barely be described as acting, so seriously does he fail to grasp the rudiments of the trade. According to the critics, Dylan 'shambles through his lines and walks around as if the camera were causing him physical pain' (Anderson, 2003). Guthmann (2003) points out that '[v]oid of inflection, Dylan doesn't act, but stands and looks uneasy in whatever space the camera is pointing. The deadness in his eyes stops the movie cold'. Dylan's illustrious co-stars come in for significantly less criticism. If they are flailing around, it is only because of the incoherence of the plot and the lack of direction. If they operate with excessive movement or overstate their lines, it is only in order to compensate for Dylan's inertia and underperformance.

The above-cited comments are representative of a remarkable degree of consensus among film critics. They are, in effect, policing the boundaries of their field (cinema) by arguing, essentially, that M\&A does not pass muster in relation to the field's requisite aesthetic criteria. If only, the critics propose, the same project had been left in the hands of critically acclaimed independent film directors such as John Sayles or Robert Altman (Homaday, 2003; Thomas, 2003), or if it had attempted to sketch out philosophical monologues in the manner of Richard Linklater (Vasquez, 2003). The film critics are performing a form of boundary work, which is, according to Valerie Fournier (2000), 'the constitution of an "independent and self-contained field of knowledge" as the basis upon which professions can build their authority and exclusivity' (p. 69). The critics are drawing attention to ideologically selective characteristics of cinema with which to construct a social boundary that highlights their field of expertise and indicates the alien status of those who do not understand the 
field's rules, such as Dylan (popular music) and Charles (television) (Lamont, 1992). This boundary work is analogous to the way scientists rhetorically deploy ideologies of science to distinguish their field of expertise from nonscientific activities (Gieryn, 1983). In marking boundaries, the critics are asserting their authority as arbiters of judgement. This assertion involves what Fournier (2000) terms the labour of division, which refers to 'the work which goes into creating and maintaining boundaries ... into making transient distinctions, categories and structures look stable, certain' and part of the order of things (Fournier, 2000: 73). The labour of division is more appropriate here than the Durkheimian notion of the division of labour because it draws attention to the considerable work that goes into the construction, maintenance and policing of boundaries.

\section{The aesthetic value of Dylan's wider oeuvre}

The analysis of the reviews demonstrates that there are, however, limits to this boundary work. A thread running through even the most caustic of the reviews is an implicit awareness and approval of the aesthetic value of Dylan's creative output. For example, the critics are pretty much unanimous in articulating praise for the soundtrack and the musical performances that run throughout the film. Even the most hostile reviewers, such as the prominent film critic Ebert (2003), who rated M\&A 0.5 out of 5 , are impressed by the performance of the child Tinashe Kachingwe, who sang The Times They Are A-Changin' "with such sweetness and conviction'. In fact, allusion to Kachingwe's rendition of this song crops up again and again in the critics' comments. The songs are said by many to be the best aspect of the film and Dylan's musical performances are deemed to be worthy of merit. Among the reviews, 50 sources produced 67 references drawing attention to the high quality of the musical performances in the film. The critics suggest that it is only when performing songs - with his consummately skilled touring band - that Dylan comes to life. Gone is the wooden actor and in his place stands a truly charismatic performer. The critics seem to agree that this is the mode of artistry that we should expect from Dylan. Instead of dabbling in arts with which he is not familiar, they say, he should return, to what he does best:

Appropriately, the actual musical performances provide the most enjoyable scenes in the film. Charles shoots Dylan (or Fate, if you must) and his band in clear, warm stage lighting, sticking with a single camera for each song. These numbers - inserted throughout the film with little regard to the accompanying narrative - provide a wonderful combination of excitement and serenity. Considering Dylan's stature and 
longevity, the recording of these songs is easily the most important aspect of a film drowning in self-importance (Schrager, 2003).

While M\&A is rejected on the basis of its failure to meaningfully connect with the film-specific criteria that accord with the state of play in contemporary cinema, it still connects to and enhances the value of Dylan's legacy. The aesthetic value of Dylan's work has been generated in a different field and is a product of the accumulation - over time - of countless evaluative judgements. Many of the most vehement critics of M\&A nod to the aesthetic value of Dylan's music and the significance of his cultural status. Yes - they concede, he is a 'great', a 'genius', and the aesthetic value of his work - beyond his celebrity capital - is thus conveyed from one field to another. Marjorie Baumgarten (2003), for example, suggests that the film is 'a thoroughly Dylanesque escapade - an imagistic, aphoristic reverie that exposes and obscures its maker in the same oblique fashion that has served him so very well all these 40 -some years'. It is noted that all the characters speak as though in Dylan lyrics (Stone, 2003), and the film is an attempt to recreate the interior of a Dylan song (Townsend, 2003). Along similar lines, M\&A is compared by critics to Dylan's long, evocative story songs, such as Sad Eyed Lady of the Lowlands, Lily, Rosemary and the Jack of Hearts, Black Diamond Bay and Highlands. When the comparison is less than favourable, it is because Dylan's songwriting style is not deemed to translate well into the cinematic medium.

\section{Popular music-field-specific aesthetic criteria}

After the hostile reviews, M\&A followed Dylan's footsteps back to the field of popular music and was warmly received by the vast majority of critics. For these critics, Dylan's songwriting imagination is seen to gain from being dramatised cinematically. Dylan is able to say things through the medium of film that he cannot say in song. Moreover, Dylan aficionados argue that critics will be disappointed with M\&A if they are expecting to see a conventional film. Steven King (2003), for example, suggests that '[i]f you thought it would be like Rambo you won't like it. If you thought it might be like Senor the movie you'll be pleased'. Rambo was a mainstream action film series starring Sylvester Stallone as a troubled Vietnam veteran. Senor is considered to be a mid-career Dylan masterpiece, revered by critics for its oblique but portentous lyrics and soundscape. The suggestion is that those 'in the know' will understand M\&A if only they arrive at the cinema with the requisite knowledge of Dylan's oeuvre, including familiarity with songs such as Senor. Those who dismiss the film, in contrast, are simply 'criticising what you can't understand' (Rose, 2003). One of 
the few positive reviews written by a film critic, Jon Pareles (2003), in the New York Times, also emphasises the relation of the film to Dylan's artistic output:

Thug, promoter, journalist, girlfriend, revolutionary, television executive, dictator, prison guard - they all speak in parables and aphorisms and wisecracks that might just be wisdom, borrowing the diction of the King James Bible and the blues. Their conversations ponder freedom, love, politics, time, conscience and death. And the tone - prophecy switching to zinger and back - is familiar to anyone who's ever heard a Dylan song.

Another film critic, Stephanie Zacharek (2003), praises the film for the way it deals with virtually every theme or motif that Dylan has written about during the course of his career. This lends M\&A the quality of a lengthy Dylan song: ' $[t]$ he intricacies and notso-hidden evils of politics, the potency of religion and symbols, hypocrisy, love betrayal: You name it, M\&A has it'. Steven Shaviro (2004) goes as far as to argue that M\&A should not be treated as a film at all. In an otherwise hostile evaluation, he concedes that it is an integral part of Dylan's oeuvre and serves to provide 'a kind of self-mythologizing metacommentary on his persona(s) and his music'. The popular music reviewers take this further, arguing that even if the film is constructed like a song, Dylan clearly had a reason for utilising this medium, in order to say things he could not articulate in a song. In Counterpunch, David Vest (2003) castigates the laziness of critics who find M\&A 'incomprehensible', which is merely a term attributed to something unfamiliar they have failed to try to understand. Long-time Dylan scholar Michael Gray (2004: 52) points out that the stylised script should not surprise anyone familiar with Dylan's writing style or his oblique interview technique. For many of the popular music critics, the film ultimately reveals Dylan's artistry and aligns him with other cultural 'greats'. Moreover, former British Poet Laureate Andrew Motion (2003) draws attention to the profoundly philosophical themes raised in M\&A concerning the value of art, the extent to which artists should interpret their work and how they might protect their artistry from detractors and admirers. According to Motion (2003), Dylan adeptly raises these themes while retaining the element of mystery that characterises his genius. Vest (2003) draws attention to M\&A's political significance in the present, thus contesting the view that the film is set in a dystopian future. He argues that M\&A is the only film he has seen this millennium 'that seems to have a clue about what is going on in America'. Dylan's performance of I'll Remember You brings to mind Allen Ginsburg's $A$ Supermarket in America, and the film, as a whole, with its urgency and intensity, 
has William Shakespeare's histories as its antecedents (Vest, 2003). But Dylan's 'film song' is not simply poetic and prophetic, it is also funny: references to the humour that runs through M\&A are made by a number of the critics from the field of popular music. They draw comparisons between the playful asides and monologues in M\&A and Dylan's quick-fire lyrics on albums such as Love \& Theft (2001).

In these reviews, we can see boundary work: many of the popular music critics appraise M\&A on the basis of their deep knowledge and understanding of Dylan's songwriting repertoire. In doing so, they distinguish themselves - as a value community with collective norms and boundaries - from those who do not 'get' Dylan (Lamont, 1992). M\&A is an in-joke for insiders, those who share this sense of group membership. The field-specific authority conveyed in the hostile reviews diminishes the status of M\&A but, at the same time, the status of M\&A is hoisted by a wider force represented in the accumulation of aesthetic value that has accrued in the course of time to Dylan's creative output. This has emerged as a supra-individual voice, like the objective culture described by Simmel (2004 [1900]), which towers over each critic as a great body of accumulated value judgements; it is the labour of countless critical voices. This supra-individual voice is heterogeneous and contains contradictory elements, positive and negative, passionate and indifferent, articulated by those well positioned in the cultural field as well as those on the margins. However, as we see in the example of the aesthetic value that has accrued to Dylan's work, it takes a particular form, given definition by the sheer volume of positive evaluative judgements.

\section{Conclusion}

If we pay heed to what was written by film critics around the time of the film's release, we see that M\&A was a vanity project enabled by Dylan's celebrity capital. It was deemed to be a 'bad film' in terms of the field-specific aesthetic criteria deployed by critics operating in the cinematic field. So, M\&A followed in Dylan's footsteps and made its journey back to the field of popular music where it was evaluated more favourably. However, the rejection of M\&A in the field of cinema could only ever be partial. It was impossible for the film critics, despite their boundary work, to ignore the aesthetic value that Dylan's wider body of work had accumulated over time. There is, then, a temporal dimension of aesthetic appraisal that needs to be considered, even when reviews are considered at a particular historical conjuncture. Georgina Born's (2010) work is useful here, and she proposes a temporal analysis that is attentive to the 'dynamics of retention and protention that map the art corpus or genre as a 
distributed object', and the 'variable temporalities constructed by the object in terms of the movement of repetition and difference, reproduction and invention in genre' (pp. 195-196). Along these lines, we need to consider the critical reception of M\&A in relation to Dylan's body of work, with its ebbs and flows of innovation and repetition and the variable modes of reception and the accumulation of aesthetic value that have accrued to it over time. In this analysis of fieldspecific aesthetic criteria, we see that boundary work is effective in diminishing the status of a cultural object (M\&A), but we also see that each critic has only limited sway in the face of the totality of judgements which emerges as a supra-individual voice, heterogeneous and full of contradictions, deriving from all those who make evaluative judgements in the field of culture. This is crystallised in the form of the institutional cultural capital deriving from prominent awards and reviews but it also takes shape in the everyday utterances of fans.

\section{Note}

1. There has not been much discussion of M\&A in academia. Two articles, however, have emerged in recent years. First, Rachel Rubin (2004) hosted a roundtable discussion of M\&A and focused, among other things, on the controversial use of the song Dixie, the references to minstrelsy, the film's intertextuality and the extent to which M\&A puts forward a political vision that might inspire collective action. The other article, written by the film scholar Murray Leeder (2012), zooms in on the significance of the brief appearance in M\&A of the ghost minstrel character Oscar Vogel. Vogel, it is argued, provides commentary both on Dylan's creative persona, 'which has long been strung on the dialect of "masking" and authenticity' (Leeder, 2012: 183), and on the ways in which modern America is haunted by memories of war, slavery and racism.

\section{References}

Alter E (2003) Masked and Anonymous. Film journal international, 2 August. Available at: https://www.rottentomatoes.com/critic/ethanalter/movies?page $=28$

Anderson J (2003) Masked and Anonymous. Combustible Celluloid. Available at: http://www. combustiblecelluloid.com/2003/maskanon.shtml (accessed 20 February 2017). 
Atkinson M (2003) It's all over now. Village Voice. Available at: http://www.villagevoice.com/ film/its-all-over-now-6397228 (accessed 20 February 2017).

Ayres L (2012) Thematic coding and analysis. In: Given LM (ed.) The Sage Encyclopaedia of Qualitative Research Methods. Thousand Oaks, CA: Sage, p.868.

Baumann S (2001) 'Intellectualization and art world development: Film in the United States'. American Sociological Review 66(3): 404-426.

Baumgarten M (2003) Film review: Masked and Anonymous. Austin Chronicle. Available at:

http://www.austinchronicle.com/calendar/film/2003-08-22/173759/

(accessed 20 February 2017).

Born G (2010) The social and the aesthetic: For a post-Bourdieuian theory of cultural production. Cultural Sociology 4(2): 171-208.

Bourdieu P (1984) Distinction: A Social Critique of the Judgement of Taste. London: Routledge.

Bourdieu P (1986 [1983]) The forms of capital. In: Richardson JG (ed.) Handbook of Theory and Research for the Sociology of Education. New York: Greenwood Press, pp.241-258.

Bourdieu P (1993) The Field of Cultural Production. Cambridge: Polity Press.

Bourdieu P (1996) The Rules of Art. Cambridge: Polity Press.

Bourdieu P (1998) On Television and Journalism. London: Pluto.

Bourdieu P (2003) Firing Back: Against the Tyranny of the Market 2. London: Verso.

Bourdieu P (2004) Science of Science and Reflexivity. Cambridge: Polity Press.

Bradshaw P (2004) The great unwatched: As dirty dancing's sequel heads straight to video, Peter Bradshaw rents a stack of Hollywood's greatest flops. The Guardian, 1 October, 7.

Braun V and Clarke V (2006) Using thematic analysis in psychology. Qualitative Research in Psychology 3(2): 77-101.

Coffey A and Atkinson J (1996) Making Sense of Qualitative Data:

Complementary Research Strategies. Thousand Oaks, CA: Sage.

Corner J (2013) 'Criticism': Notes on the circulation of cultural judgement. JOMEC Journal. Epub ahead of print 8 November. DOI: 10.18573/j.2013.10260.

Dana W (2004) Masked and Anonymous. Rolling Stone, 4 March, p. 943.

Davies N (2003) Nick's Flick Picks review of Masked and Anonymous. NicksFlickPicks. Available at: 
http://www.nicksflickpicks.com/maskanon.html (accessed 20 February 2017).

Driessens O (2013) Celebrity capital: Redefining celebrity using field theory. Theory \& Society 42(5): 543-560.

Ebert R (2003) Masked and Anonymous movie review (2003). Rogerebert.com.

Available at: http:// www.rogerebert.com/reviews/masked-andanonymous-2003 (accessed 20 February 2017).

Errigo A (2003) Masked and Anonymous. Empire. Available at: http://www.empireonline.com/ movies/masked-anonymous/review/ (accessed 20 February 2017).

Fielding N and Thomas H (2008) Qualitative interviewing. In: Gilbert N (ed.) Researching Social Life. London: Sage, pp.245-265.

Fournier V (2000) Boundary work and the (un-)making of the professions. In:

Malin N (ed.) Professionalism, Boundaries and the Workplace. London: Routledge, pp.67-86.

Fowler B (2016) Bourdieu, field of cultural production and cinema. In: Austin G (ed.) New Uses of Bourdieu in Film and Media Studies. New York: Berghahn, pp.13-34.

Frith S (1989) World Music, Politics and Social Change: Papers from the International Association for the Study of Popular Music. Manchester:

Manchester University Press.

Garnham N (1993) Bourdieu, the cultural arbitrary, and television. In: Calhoun

C, LiPuma E and Postone M (eds) Bourdieu: Critical Perspectives. Chicago,

IL: University of Chicago Press, pp.178-192.

Gieryn T (1983) Boundary-work and the demarcation of science from nonscience: Strains and interests in professional ideologies of scientists. American Sociological Review 48(6): 781-795.

Giles DC (2015) Field migration, cultural mobility and celebrity: The case of Paul McCartney. Celebrity Studies 6(4): 538-552.

Gonsalves R (2015) The survival of the friendliest: Contemporary Indian publishing in English at the Frankfurt Book Fair. Cultural Sociology 9(3): 425-446.

Gray M (2004) Observer music monthly: A few of our favorite things: DVD:

Sometimes it gets so hard to see. The Observer Music Magazine, 25 April, 52.

Guthmann E (2003) FILM CLIPS / also opening today. SFGate. Available at: http://www. 
sfgate.com/movies/article/FILM-CLIPS-Also-opening-today-2599082.php

(accessed 20 February 2017).

Harrington A (2004) Art and Social Theory: Sociological Arguments in

Aesthetics. Cambridge: Polity Press.

Hennion A (2001) Music lovers: Taste as performance. Theory, Culture \& Society 18(5): 1-22.

Hennion A (2007) Those things that hold us together: Taste and sociology.

Cultural Sociology 1(1): 97-114.

Highmore B (2016) Taste as feeling. New Literary History 47(4): 547-566.

Homaday A (2003) 'Masked': Riddled with Dylan. The Washington Post. Available at: http:// www.washingtonpost.com/wpdyn/content/article/2003/09/05/AR2005040200611.html (accessed 20 February 2017).

Jacobs RS, Heuvelman A, Allouch SB, et al. (2015) Everyone's a critic: The power of expert and consumer reviews to shape readers' post-viewing motion picture evaluations. Poetics 52: 91-103.

Kant I (2008 [1790]) Critique of judgement. In: Cahn SM and Meskin A (eds) Aesthetics: A Comprehensive Anthology. Oxford: Blackwell, pp.131-166.

Kersten A and Bielby DD (2012) Film discourse on the praised and acclaimed:

Reviewing criteria in the United States and United Kingdom. Popular Communication 10(3): 183-200.

King S (2003) Review. Maskedandanonymousdatabase.blogspot.co.uk. Available at: http://

maskedandanonymousdatabase.blogspot.com/p/sundancereviews.html (accessed 1 July 2019).

Lacey L (2003) Like a sinking stone. The Globe and Mail. Available at: http://www.theglobeandmail.com/arts/like-a-sinking-stone/article752195/ (accessed 20 February 2017).

Lamont M (1992) Money, Morals, \& Manners: The Culture of the French and the American Upper-Middle Class. Chicago, IL: University of Chicago Press.

Lane J (2003) Masked and Anonymous. Sacramento News \& Review. Available at: https://www.

newsreview.com/sacramento/masked-anonymous/content?oid=16349 (accessed 20 February 2017).

Leeder M (2012) Haunting and minstrelsy in Bob Dylan's Masked and Anonymous. Journal of Popular Film and Television 40(4): 181-191. 
Lumenick L (2003) Positively 4th rate. New York Post. Available at: http://nypost.com/2003/07/24/ positively-4th-rate/ (accessed 20 February 2017).

McCarthy T (2003) Review: 'Masked and Anonymous'. Variety. Available at: https://variety. com/2003/film/reviews/masked-and-anonymous-21200543665/

Motion A (2003) Masked and Anonymous: About the movie: Andrew motion essay. Sonyclassics.

com. Available at: http://www.sonyclassics.com/masked/andrew-motionessay.html (accessed 20 February 2017).

Pareles J (2003) FILM; Bob Dylan plays Bob Dylan, whoever that is. The New York Times. Available at: http://www.nytimes.com/2003/07/27/movies/filmbob-dylan-plays-bob-dylanwhoever-that-is.html (accessed 20 February 2017).

Peary G (2003) Masked and Anonymous. Available at: http://www.geraldpeary.com/reviews/ mno/masked-and.html (accessed 20 February 2017).

Peterson RA and Kern RM (1996) Changing highbrow taste: From snob to omnivore. American Sociological Review 61: 900-907.

Phipps K (2003) Masked and Anonymous. AVCLUB. Available at: http://www.avclub.com/ review/masked-and-anonymous-5536 (accessed 20 February 2017).

Puig C (2003) Also opening: 'Buffalo soldiers', 'Masked and Anonymous', 'I capture the castle'. USA Today. Available at: http://usatoday30.usatoday.com/life/movies/reviews/2003-0725alsoopening_x.htm (accessed 20 February 2017).

Rainer P (2003) Love bites. New York. Available at: http://nymag.com/nymetro/movies/ reviews/n_9050/ (accessed 20 February 2017).

Rojek C (2000) Celebrity. London: Reaktion.

Rose A (2003) Review. Maskedandanonymousdatabase. blogspot.co.uk. Available at: http://

maskedandanonymousdatabase.blogspot.com/p/sundancereviews.html (accessed 1 July 2019).

Rubin R (2004) Roundtable discussion on Dylan's Masked and Anonymous. Journal of Popular Music Studies 16(3): 242-282. 
Savage M and Silva EB (2013) Field analysis in cultural cociology. Cultural Sociology 7(2): 111-126.

Schrager N (2003) Masked \& Anonymous. Contactmusic.com. Available at: http://www.contactmusic.com/film/review/maskedanonymous (accessed 20 February 2017).

Scott A (2003) FILM REVIEW; Times they are surreal in Bob Dylan tale. The New York Times. Available at:

http://www.nytimes.com/2003/07/24/movies/film-review-times-theyare-surreal-in-bob-dylan-tale.html (accessed 20 February 2017).

Shaviro S (2004) Masked and Anonymous - The Pinocchio theory. Shaviro.com. Available at:

http://www.shaviro.com/Blog/?p=296 (accessed 20 February 2017).

Simmel G (2004 [1900]) The Philosophy of Money. London, Routledge.

Stewart S (2012) Reflections on sociology and aesthetic value. Distinktion: Scandinavian Journal of Social Theory 13(2): 153-167.

Stewart S (2013) Evaluating culture: Sociology, aesthetics and policy. Sociological Research Online 18(1): 1-10.

Stewart S (2017) Evaluative judgements: Ethics, aesthetics and 'bad taste'. The Sociological Review 65(1): 37-51.

Stone J (2003) Troubador trouble: Get beyond the weird plot and Bob Dylan's acting, and this film can be fun. Ottowa Citizen, 24 October, D1.

Thayil J (2003) An exercise in evasion and bloat. Rediff.com. Available at: http://www.rediff.com/ movies/2003/aug/07mask.htm (accessed 20 February 2017).

Thomas K (2003) A self-indulgent 'Masked' has more tedium than allegory. Los Angeles Times. Available at: http://articles.latimes.com/2003/jul/25/entertainment/et-masked25 (accessed 20 February 2017).

Townsend B (2003) The Dylan show; legend weaves not so simple twists of fate. The Atlanta Journal-Constitution, 22 August, $1 \mathrm{E}$.

Travers P and Scaggs A (2003) Movie review: Bob Dylan and 'Masked and Anonymous'. Rolling Stone. Available at: http://www.rollingstone.com/music/news/movie-review-bob-dylanandmasked-and-anonymous-20030821 (accessed 20 February 2017).

Vasquez F (2003) Masked and Anonymous (2003). Cinema Crazed. Available at: http://cinemacrazed.com/blog/2004/08/29/masked-and-anonymous2003/ (accessed 20 February 2017). 
Vest D (2003) Masked and Anonymous, Dylan's elegy for a Lost America. CounterPunch. Available at:

http://www.counterpunch.org/2003/09/19/masked-and-anonymousdylan-selegy-for-a-lost-america/ (accessed 20 February 2017).

Weber M (1946 [1915]) From Max Weber: Essays in Sociology. London: Routledge.

Zacharek S (2003) Dylan in darkest America. Salon. Available at: http://www.salon.

com/2003/07/24/masked_anonymous/ (accessed 20 February 2017).

\section{Biographical note}

Simon Stewart is Senior Lecturer in Sociology at University of Portsmouth. His current research is concerned with theorizing evaluative judgements and the processes through which we decide what is to be prized. Simon is the author of Culture and the Middle Classes (Ashgate, 2010) and A Sociology of Culture, Taste and Value (Palgrave Macmillan, 2014). 